\title{
Cognitive function of elderly residents in long-term institutions: effects of a physiotherapy program
}

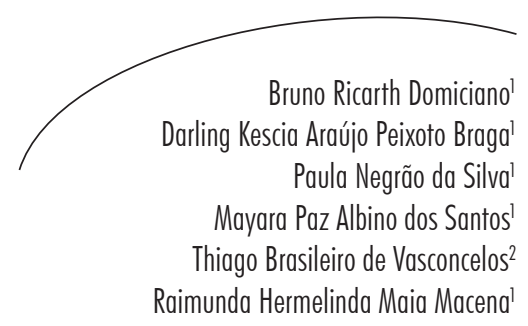

\section{Abstract}

The increase in the size of the elderly population demands new knowledge about the process of healthy and active aging. Cognitive disorders are directly associated with aging, and therefore represent a public health problem. A longitudinal and interventional study with a quantitative approach was performed with the aim of analyzing the effects of a physical therapy program aimed at health promotion on the cognitive ability of institutionalized elderly women. Data was collected using a sociodemographic and clinical form and the Mini Mental State Examination (MMSE) at three time points (baseline, after 10 interventions and after 20 interventions). The health promotion program consisted of 20 recreational group activities in weekly meetings lasting an hour. Statistical analysis used the paired Student's t-test and Analysis of variance, with a significance level of $p<0.05$. The sample consisted of 24 elderly persons, with a mean age of 80.04 years. The results showed improvement in the performance of the elderly, both in overall MMSE score $(\mathrm{T} 0=19.22 v$ s. $\mathrm{T} 2=28.33, p=0.01)$ and in the evaluated subcategories "time orientation" ( $\mathrm{T} 0=3.35 v \mathrm{v}$. T2 $=3.57, p=0.02)$, "record" ( $\mathrm{T} 0=2.61 v \mathrm{~s}$. $\mathrm{T} 2=2.95, p<0.01)$, "memory recall" (T0=1.78 vs. T2=2.71, $p<0.01)$, "read and execute" ( $\mathrm{T} 0=0.43 v$ s. T2 $=0.67, p=0.01)$ and "copy diagram" ( $\mathrm{T} 0=0.26$ vs. T2 $=0,48, p=0.02$ ). These findings suggest that physical therapy for health promotion purposes enables improvement in performance of cognitive activities of institutionalized elderly persons, thus contributing to a better quality of life.

\footnotetext{
Universidade Federal do Ceará, Centro de Ciências da Saúde, Faculdade de Medicina, Departamento de Fisioterapia, Curso de Fisioterapia. Fortaleza, CE, Brasil.

2 Universidade Federal do Ceará, Centro de Ciências da Saúde, Faculdade de Medicina, Departamento de Fisiologia e Farmacologia. Fortaleza, CE, Brasil.

Study funding: Fundação Cearense de Apoio ao Desenvolvimento Científico e Tecnológico (Cearense Foundation for the Support of Scientific and Technological Development) (FUNCAP), Programa Institucional de Bolsas de Iniciação Científica (Institutional Scientific Initiation Scholarship Program) (PIBIC), Public Notice no $01 / 2013$.
}

Key words: Elderly; Cognition; Physical Therapy Specialty; Homes for the Aged. 


\section{INTRODUCTION}

Global populations are undergoing a rapid process of aging, a demographic change which occurs more rapidly in low and middle-income countries and has a significant impact in the healthcare, social and economic sectors of all countries. ${ }^{1}$ As with every human situation, aging has an existential dimension, which modifies a person's relationship with time, generating changes in their relations with the world and with their own history. ${ }^{2}$

Levels of cognitive disorder increase as a population ages, meaning that there is a current global rise in the same, constituting a major mental health problem. ${ }^{3}$ In this sense several studies ${ }^{4-6}$ have highlighted the relationship between aging and the onset of cognitive disorders (dementia, reaction time, memory deficit, understanding and learning), also describing how such disorders can be influenced by factors such as age, education, physical activity and income. ${ }^{4,6}$

The assessment of cognitive ability has arisen, therefore, as a new health paradigm, of particular importance for the elderly, originating from the concept of health and quality of life, combined with increased life expectancy. ${ }^{7}$ One method for checking the health conditions of the elderly is the application of instruments that allow the overall assessment of these individuals by a health team, addressing their individual, family and social conditions and their relationship with functional, cognitive and affective capacity. ${ }^{8}$

Thus, evaluation of the cognitive capacity of institutionalized elderly persons -enables the selection of appropriate interventions to combat foreseeable dependencies and allows the promotion of a more active and healthy lifestyle.

Faced with an aging population, measures of early intervention by health professionals become necessary in order to prevent cognitive harm and to change misguided attitudes that endanger the health of the elderly, thus providing greater autonomy and a better quality of life. ${ }^{10}$

Taking the above into consideration, the present study aimed to analyze the effects of a physiotherapy program for the promotion of health based on the cognitive capacity of institutionalized elderly women.

\section{METHOD}

A longitudinal, interventional and analytic study with a quantitative approach was conducted from December 2013 to April 2014 in two private and philanthropic long-term care facilities for the elderly (LTCFEs) with exclusively female patients, located in the city of Fortaleza, in the state of Ceará. This study formed part of the Programa de Extensão Promoção da Saúde (Program for the Extension of Health Promotion) (PROSA) of the course of Physiotherapy, Universidade Federal do Ceará (Federal University of Ceará).

The sample consisted of elderly persons aged 65 and over and resident in at least one of the LTCFEs. A single researcher addressed these individuals verbally and explained the purpose of the study to them. Having agreed to participate in the survey they were evaluated for a basic knowledge of mathematics (in other words that they were able to perform mental calculations) and that they were willing to attend $75 \%$ of the activities developed for the promotion of health.

Any individuals who had proven medical diagnosis of previous and/or progressive neurodegenerative disorders, alteration of allopsychic and autopsychic orientation in relation to personal contact, or who were using specific medications for the improvement of cognitive function were excluded. The directors of the LTCFEs were consulted and informed about the feasibility of the study, and agreed to let it be carried out. 
Data collection took place in three stages: initial diagnosis (T0) assessment for review of the intervention plan (T1) and final evaluation (T2). The initial diagnosis was performed using a formula for socio-demographic and nosological characterization of the sample, prepared by the authors of the study, together with the Mini Mental State Examination (MMSE), an instrument originally proposed by Folstein et al. ${ }^{11}$ in 1975, validated for use in Portuguese in 1994 by Bertolucci et al. ${ }^{12}$ and modified by Brucki et al. ${ }^{13}$ in 2003 (Chart 1) for cognitive assessment of the elderly. The MMSE consists of questions grouped into seven categories (orientation to time, orientation to place, registration, attention and calculation, memory recall, language and visual constructive capacity). Total score can range from zero to a maximum of 30 points. In this test, values of higher than 27 points are considered normal with values indicating dementia being those lower than or equal to 24 points. In patients with less than four years of schooling, the cutoff point is 17 , rather than 24 points. ${ }^{14}$

Chart 1. Mini Mental State Examination (MMSE).

\begin{tabular}{|c|c|}
\hline Orientation of time (5 points) & $\begin{array}{l}\text { 1. What is the approximate time? } \\
\text { 2. What day of the week is it? } \\
\text { 3. Which day of the month is it today? } \\
\text { 4. In which month are we? } \\
\text { 5. In which year are we? }\end{array}$ \\
\hline Orientation of place (5 points) & $\begin{array}{l}\text { 1. Where are we? } \\
\text { 2. What is this place? } \\
\text { 3. In which neighborhood are we or at what address? } \\
\text { 4. In which city are we? } \\
\text { 5. In which state are we? }\end{array}$ \\
\hline Register (3 points) & Repeat: car, vase, brick \\
\hline Attention and calculation (5 points) & Subtract: $100-7=93-7=86-7=79-7=72-7=65$ \\
\hline Memory recall (3 points) & What three objects were asked earlier? \\
\hline Name two objects (2 points) & Watch and pen \\
\hline Repeat (1 points) & "Neither here nor there, nor there" \\
\hline Stage command (3 points) & $\begin{array}{l}\text { Pick up this piece of paper with your right hand, fold it in } \\
\text { half and put it on the floor }\end{array}$ \\
\hline Write a complete sentence (1 point) & Write a sentence that makes sense \\
\hline Read and execute (1 point) & Close your eyes \\
\hline Copy diagram (1 point) & Copy two intersecting pentagons \\
\hline
\end{tabular}


The second test was performed after the execution of 10 activities (T1) and the third after 20 activities (T2); with the MMSE being reapplied in both cases.

The interventions were carried out by two academics from the Federal University of Ceará; supervised by professional physiotherapists from the planning stage of the promoted activities until their execution. The program had a total duration of five months and was carried out in weekly meetings lasting at least one hour. It is worth noting that the performance of the activities normally took the minimum amount of time.
During the execution of the activities, group techniques were utilized in order to ensure a collective perspective and interactive manner with the elderly individuals (Table 2). The exercises were carried out with the help of physiotherapy equipment, such as elastic bands, bats and balls, and homemade materials, such as plastic bottles and strings, in accordance with the aim set for the week's activity. The interventions were carried out in the main hall of each LTCFE. The instruments used in the intervention plan were: a fieldwork diary (for making important notes during the interventions), the oral reports of the elderly persons, participant observation, intervention protocol and action reports (describing all the actions performed at the end of each intervention).

Chart 2. Intervention protocols, themes, activities performed and therapeutic objectives. Fortaleza, CE, 2014.

\begin{tabular}{|c|c|c|}
\hline $\begin{array}{l}\text { Protocol 1- } \\
\text { Cognitive function }\end{array}$ & $\begin{array}{l}\text { Objective: To promote improved } \\
\text { motor skills and to stimulate } \\
\text { reasoning and memory. } \\
\text { Objective: To promote improved } \\
\text { motor skills and stimulate reasoning, } \\
\text { memory and the ability to solve } \\
\text { "problematic" situations. }\end{array}$ & $\begin{array}{l}\text { Activity 1: Circle the drawings equal to } \\
\text { those that were separated in a picture; draw } \\
\text { geometric figures. } \\
\text { Activity 2: Connect points; making various } \\
\text { body movements (like beating the right } \\
\text { hand on the left breast, hitting a foot on the } \\
\text { ground). } \\
\text { Activity 3: Guessing game: connect points } \\
\text { and discover which drawings are formed. } \\
\text { Activity 4: Each elderly person is expected } \\
\text { to adopt the characteristic sound of that } \\
\text { animal/object that appears in their prints } \\
\text { and the others try to guess. }\end{array}$ \\
\hline Protocol 2- Music & $\begin{array}{l}\text { Objective: To promote improved } \\
\text { motor skills and stimulate reasoning, } \\
\text { memory and the ability to solve } \\
\text { "problematic" situations. }\end{array}$ & $\begin{array}{l}\text { Activity 5: Songs by Roberto Carlos } \\
\text { (such as Jesus Cristo and Nossa Senhora } \\
\text { among others) were used for singing and } \\
\text { memorization of the lyrics and melodies; } \\
\text { then an assembly was played with mixed } \\
\text { excerpts of these songs for the elderly to } \\
\text { sing the lyrics correctly. }\end{array}$ \\
\hline $\begin{array}{l}\text { Protocol 3- } \\
\text { Prevention of falls }\end{array}$ & $\begin{array}{l}\text { Objective: To promote improved } \\
\text { motor skills and stimulate reasoning, } \\
\text { memory and communication. }\end{array}$ & $\begin{array}{l}\text { Activity 6: Talk about each elderly person's } \\
\text { history of falls; the elderly were divided into } \\
\text { smaller groups and each group received the } \\
\text { game "Lookout for Risks" in order for the } \\
\text { correct associations to be made. }\end{array}$ \\
\hline
\end{tabular}




\begin{tabular}{|c|c|c|}
\hline $\begin{array}{l}\text { Protocol 4- } \\
\text { Personal hygiene }\end{array}$ & $\begin{array}{l}\text { Objective: To promote improved } \\
\text { motor skills and stimulate } \\
\text { reasoning, memory, the ability to } \\
\text { solve "problematic" situations and } \\
\text { communication. }\end{array}$ & $\begin{array}{l}\text { Activity } 7 \text { : Various personal hygiene } \\
\text { products were mixed with various other } \\
\text { objects and placed in a box. This box was } \\
\text { circulated amongst the elderly for each of } \\
\text { them to pick up an important object for } \\
\text { hygiene and state what it is and what it } \\
\text { achieves. }\end{array}$ \\
\hline $\begin{array}{l}\text { Protocol 5- } \\
\text { Religiousness }\end{array}$ & $\begin{array}{l}\text { Objective: To promote improved } \\
\text { motor skills and stimulate reasoning. }\end{array}$ & Activity 8: Making a rosary. \\
\hline $\begin{array}{l}\text { Protocol 6- Healthy } \\
\text { eating }\end{array}$ & $\begin{array}{l}\text { Objective: To stimulate reasoning, } \\
\text { memory and the ability to } \\
\text { solve situations "problems" and } \\
\text { communication. }\end{array}$ & $\begin{array}{l}\text { Activity 9: The elderly individuals were } \\
\text { asked which foods they liked and which } \\
\text { they thought were good for their health; } \\
\text { importance of having a healthy diet was } \\
\text { discussed, as were the typical restricted } \\
\text { diets for patients who have systemic arterial } \\
\text { hypertension (SAH) and diabetes mellitus } \\
\text { (DM), and the importance of following this } \\
\text { diet correctly. }\end{array}$ \\
\hline $\begin{array}{l}\text { Protocol } 7 \text { - } \\
\text { Collages/mosaics }\end{array}$ & $\begin{array}{l}\text { Objective: To promote improved } \\
\text { motor skills and stimulate reasoning, } \\
\text { memory and the ability to solve } \\
\text { "problematic" situations. }\end{array}$ & $\begin{array}{l}\text { Activity 10: We took up cutouts of } \\
\text { geometric shapes for the elderly to make } \\
\text { into objects such as a car and the Brazilian } \\
\text { flag. }\end{array}$ \\
\hline $\begin{array}{l}\text { Protocol 8- Beauty } \\
\text { day }\end{array}$ & $\begin{array}{l}\text { Objective: To stimulate memory and } \\
\text { the ability to solve "problematic" } \\
\text { situations. }\end{array}$ & $\begin{array}{l}\text { Activity 11: We took miscellaneous items } \\
\text { used for beautification (makeup, hair } \\
\text { accessories and perfume, among others.). } \\
\text { The elderly identified these objects and } \\
\text { spoke about their usefulness. }\end{array}$ \\
\hline Protocol 9- Posters & $\begin{array}{l}\text { Objective: To promote improved } \\
\text { motor skills and stimulate reasoning, } \\
\text { memory and the ability to solve } \\
\text { "problematic" situations. }\end{array}$ & $\begin{array}{l}\text { Activity 12: The elderly were separated } \\
\text { into three tables. Each table received a } \\
\text { card and pictures that were related to the } \\
\text { previous protocols of nutrition, hygiene } \\
\text { and prevention of falls; the table which } \\
\text { received the nutrition theme received a card } \\
\text { with a picture of four plates and several } \\
\text { print outs of food (healthy and unhealthy). } \\
\text { Participants selected from the pictures in } \\
\text { order to assemble four dishes (breakfast, } \\
\text { lunch, afternoon snack, dinner) made up of } \\
\text { healthy foods. }\end{array}$ \\
\hline $\begin{array}{l}\text { Protocol 10- } \\
\text { Carnival }\end{array}$ & $\begin{array}{l}\text { Objective: To promote improved } \\
\text { motor skills and stimulate reasoning } \\
\text { and memory. }\end{array}$ & $\begin{array}{l}\text { Activity 13: Making carnival masks; during } \\
\text { the activity old carnival marches were } \\
\text { played, so that the elderly could remember } \\
\text { them and sing along. }\end{array}$ \\
\hline
\end{tabular}




\begin{tabular}{|c|c|c|}
\hline Protocol 11- Puzzles & $\begin{array}{l}\text { Objective: To promote improved } \\
\text { motor skills and stimulate reasoning, } \\
\text { memory and the ability to solve } \\
\text { "problematic" situations. }\end{array}$ & $\begin{array}{l}\text { Activity 14: The elderly were divided into } \\
\text { three groups, each receiving a puzzle. The } \\
\text { assembled puzzles were shown and the } \\
\text { elderly persons were asked to memorize all } \\
\text { of the details. Then they were dismantled } \\
\text { and each group were asked to reassemble } \\
\text { one. }\end{array}$ \\
\hline $\begin{array}{l}\text { Protocol 12- } \\
\text { Puzzles }\end{array}$ & $\begin{array}{l}\text { Objective: To stimulate reasoning, } \\
\text { memory and the ability to solve } \\
\text { "problematic" situations. }\end{array}$ & $\begin{array}{l}\text { Activity 15: The elderly were separated } \\
\text { into three groups. Several objects were } \\
\text { grouped in a random sequence (e.g., } 4 \\
\text { objects, } 8 \text { objects, } 1 \text { object, } 6 \text { objects). First, } \\
\text { the elderly were required to say how many } \\
\text { objects were in each arrangement; then, } \\
\text { they were asked to remember the number } \\
\text { of the amount of each object. Finally, each } \\
\text { group had to read out the correct sequence } \\
\text { (e.g. for the previous example: } 4,8,1,6) \text {. }\end{array}$ \\
\hline $\begin{array}{l}\text { Protocol } 13- \\
\text { Forming words }\end{array}$ & $\begin{array}{l}\text { Objective: To stimulate reasoning, } \\
\text { memory and the ability to solve } \\
\text { "problematic" situations. }\end{array}$ & $\begin{array}{l}\text { Activity 16: Several letters were distributed } \\
\text { to the elderly for them to form the correct } \\
\text { word being referred to. }\end{array}$ \\
\hline $\begin{array}{l}\text { Protocol 14- } \\
\text { Hangman }\end{array}$ & $\begin{array}{l}\text { Objective: To stimulate reasoning, } \\
\text { memory and the ability to solve } \\
\text { "problematic" situations. }\end{array}$ & $\begin{array}{l}\text { Activity 17: Playing hangman, using } \\
\text { themes related to the activities already } \\
\text { implemented and relevant to health. }\end{array}$ \\
\hline $\begin{array}{l}\text { Protocol 15- Game } \\
\text { of sensations }\end{array}$ & $\begin{array}{l}\text { Objective: To promote improved } \\
\text { motor skills and stimulate reasoning, } \\
\text { memory and the ability to solve } \\
\text { "problematic" situations. }\end{array}$ & $\begin{array}{l}\text { Activity 18: The elderly were blindfolded } \\
\text { and received objects, which they identified } \\
\text { by smell, taste, sound and feel. }\end{array}$ \\
\hline Protocol 16- Easter & $\begin{array}{l}\text { Objective: To promote improved } \\
\text { motor skills and stimulate reasoning, } \\
\text { memory and the ability to solve } \\
\text { "problematic" situations. }\end{array}$ & $\begin{array}{l}\text { Activity 19: Making bunny masks, } \\
\text { preparing and painting them. }\end{array}$ \\
\hline $\begin{array}{l}\text { Protocol 17- } \\
\text { Musical bingo }\end{array}$ & $\begin{array}{l}\text { Objective: To stimulate reasoning, } \\
\text { memory and the ability to solve } \\
\text { "problematic" situations. }\end{array}$ & $\begin{array}{l}\text { Activity 20: Bingo cards with images } \\
\text { (instead of numbers) were distributed. A } \\
\text { CD then played the sounds corresponding } \\
\text { to the images on the cards in a random } \\
\text { order. }\end{array}$ \\
\hline
\end{tabular}


It is also worth noting that researchers made no payment to the participants with respect to proposed activities, and the participants did not know the purpose of the study. The data was analyzed jointly according to the consensus of the researchers.

For comparison between groups (T0, T1 and T2) the Student $t$-test was used, paired with the Analysis of Variance (ANOVA), with a significance level of $p<0.05(5 \%)$ and a confidence interval of $95 \%$.

The ethical questions of the study were dealt with in Resolution No. 466/12..$^{15}$ The study was approved by the "Comitê de Ética em Pesquisa da Universidade Federal do Ceará” (Research Ethics Committee of the Universidade Federal do Ceará), (Protocol 327/11) and all participants signed a Free and Informed Consent Form.

\section{RESULTS}

The sample consisted of 24 elderly women $(n=19$ from LTCFE 1 and $n=5$ from LTCFE 2$)$, with an average age of $80.42 \pm 7.95$ years [ $\mathrm{min}=65$ and $\max =90$ ], $62.5 \%$ of whom were aged between 80 and 90 . Most came from municipalities in the interior of the state of Ceara $(58.33 \%)$, were single $(66.66 \%)$ and had either a low level of education or no education $(62.50 \%)$. All were retired (100\%). Most made continuous use of medication (83.33\%), with hypoglycemic and antihypertensive drugs the most commonly used.

When cognition was investigated, the elderly individuals were almost all identified as oriented, and able to obey simple instructions (95.83\%). However, there was a presence of recurring forgetfulness (50\%), with a progressive worsening in the frequency of forgetfulness (41.67\%), which manifested itself in previous cognitive alterations in just $20.83 \%$ of cases (Table 1 ).

Table 1. Characteristics of the elderly persons studied. Fortaleza, CE, 2014.

\begin{tabular}{llll}
\hline Variables & Fa & F\% \\
\hline
\end{tabular}

Socio-demographic Characteristics

Age group

65 to 69 years

80 to 90 years

Civil Status

Married

Divorced

Single

Widowed

Education

Illiterate

Elementary incomplete

Elementary complete

Secondary complete

Higher complete 


\begin{tabular}{|c|c|c|}
\hline Variables & $\mathrm{Fa}$ & $\mathrm{F} \%$ \\
\hline \multicolumn{3}{|l|}{ Profession } \\
\hline Autonomous & 3 & 12.50 \\
\hline Salaried & 12 & 50.00 \\
\hline From home & 9 & 37.50 \\
\hline \multicolumn{3}{|l|}{ Place of birth } \\
\hline Fortaleza & 7 & 29.17 \\
\hline Municipalities in the state interior & 14 & 58.33 \\
\hline Municipalities in other states & 3 & 12.50 \\
\hline \multicolumn{3}{|l|}{ Clinical characteristics } \\
\hline Visual deficit & 15 & 62.50 \\
\hline Auditory deficit & 6 & 25.00 \\
\hline Use of medications & 20 & 83.33 \\
\hline Clinical trials: Whisper test & 7 & 29.17 \\
\hline Alcohol use & 1 & 4.17 \\
\hline Tobacco use & 3 & 12.50 \\
\hline \multicolumn{3}{|l|}{ Cognition } \\
\hline Presence of forgetfulness & 12 & 50.00 \\
\hline Previous change in functioning & 5 & 20.83 \\
\hline Progressive worsening of forgetfulness & 10 & 41.67 \\
\hline \multicolumn{3}{|l|}{ Mental state } \\
\hline Oriented and follows simple instructions & 23 & 95.83 \\
\hline Disoriented, but can obey simple instructions. & 1 & 4.17 \\
\hline \multicolumn{3}{|l|}{ Time institutionalized } \\
\hline Less than 1 year & 4 & 16.67 \\
\hline 1 to 5 years & 8 & 33.33 \\
\hline 6 to 10 years & 10 & 41.67 \\
\hline More than 10 years & 2 & 8.33 \\
\hline
\end{tabular}

$\mathrm{Fa}=$ absolute frequency; $\mathrm{F} \%=$ relative frequency. 
There was a general increase in MMSE scores before and after the physiotherapeutic intervention $(\mathrm{T}=19.22 ; \mathrm{T} 1=23.43 ; \mathrm{T} 2=28.33)$, although this was not statistically significant between the three time periods evaluated $(p=0.11)$. In all subcategories, increases in values between T0 and T2 were observed. However, progressive gains (T0-T1-T2) were seen only in the following subcategories: "register" (2.61; 2.90; 2.95), "memory recall" (1.78; 2.62; 2.71), "read and execute" $(0.43$; $0.48 ; 0.67)$ and "copy diagram" (0.26; 0.38; 0.48); with a statistically significant difference found only in "memory recall" $(p<0.01)$ (Table 2).

Table 2. Comparing responses to the Mini Mental State Examination (MMSE) of elderly persons from long-term care facilities before and after 10 and 20 physiotherapy care sessions. Fortaleza, CE, 2014.

\begin{tabular}{lcccc}
\hline \multicolumn{1}{c}{ Variables } & T0 & T1 & T2 & $p^{\text {**** }}$ \\
\hline MMSE (general) & $19.22 \pm 6.35$ & $23.43 \pm 7.35$ & $28.33 \pm 7.95$ & 0.11 \\
Orientation of time & $3.35 \pm 1.87$ & $3.14 \pm 1.88$ & $3.57 \pm 1.66$ & 0.70 \\
Orientation of place & $3.83 \pm 1.56$ & $3.90 \pm 1.70$ & $3.90 \pm 1.67$ & 0.98 \\
Register & $2.61 \pm 0.72$ & $2.90 \pm 0.44$ & $2.95 \pm 0.22$ & 0.09 \\
Attention and calculation & $0.87 \pm 1.84$ & $0.38 \pm 1.16$ & $2.29 \pm 1.10$ & 0.34 \\
Memory recall & $1.78 \pm 1.17$ & $2.62 \pm 0.80$ & $2.71 \pm 0.72$ & $<0.01$ \\
Name two objects & $2.00 \pm 0.00$ & $1.95 \pm 0.22$ & $2.00 \pm 0.00$ & 0.62 \\
Repeat & $0.91 \pm 0.29$ & $1.10 \pm 0.44$ & $1.05 \pm 0.50$ & 0.60 \\
Stage command & $2.78 \pm 0.74$ & $2.38 \pm 1.02$ & $2.71 \pm 0.72$ & 0.37 \\
Read and execute & $0.43 \pm 0.51$ & $0.48 \pm 0.51$ & $0.67 \pm 0.48$ & 0.16 \\
Speak back a phrase & $0.39 \pm 0.50$ & $0.57 \pm 0.51$ & $0.52 \pm 0.51$ & 0.49 \\
Copy diagram & $0.26 \pm 0.45$ & $0.38 \pm 0.50$ & $0.48 \pm 0.51$ & 0.36 \\
\hline
\end{tabular}

$\mathrm{T} 0=$ evaluation of baseline (average \pm standard deviation); $\mathrm{T} 1=$ evaluation after 10 physiotherapy sessions (average \pm standard deviation); $\mathrm{T} 2=$ evaluation after 20 physiotherapy sessions (average \pm standard deviation); ****ANOVA.

A statistically significant improvement in MMSE performance before and after 20 physiotherapeutic interventions was observed ( $\mathrm{T} 0=19.22$ vs. $\mathrm{T} 2=28.33, p=0.01)$. In all subcategories increases were observed between T0 and T2, except in "name two objects" $(2.00 ; 2.00)$ and "stage command"
$(2.78,2.71)$. There was a significant difference between "orientation of time" (3.35; 3.57; $\mathrm{p}=0.02)$; "register" (2.61, 2.95; $p<0.01)$; "memory recall" (1.78; 2.71; $\mathrm{p}<0.01)$, "read and execute" $(0.43 ; 0.67$; $p=0.01)$ and "copy diagram" $(0.26 ; 0.48 ; p=0.02)$ (table 3). 
Table 3. Comparing the responses to the Mini Mental State Examination (MMSE) of elderly persons from long-term care facilities before and after 10 and 20 physiotherapy sessions. Fortaleza, CE, 2014.

\begin{tabular}{lccc}
\hline \multicolumn{1}{c}{ Variables } & T0 & T2 & p*** \\
\hline MMSE (general) & $19.22 \pm 6.35$ & $28.33 \pm 7.95$ & 0.01 \\
Orientation of time & $3.35 \pm 1.87$ & $3.57 \pm 1.66$ & 0.02 \\
Orientation of place & $3.83 \pm 1.56$ & $3.90 \pm 1.67$ & 0.40 \\
Register & $2.61 \pm 0.72$ & $2.95 \pm 0.22$ & $<0.01$ \\
Attention and calculation & $0.87 \pm 1.84$ & $2.29 \pm 1.10$ & 0.09 \\
Memory recall & $1.78 \pm 1.17$ & $2.71 \pm 0.72$ & $<0.01$ \\
Name two objects & $2.00 \pm 0.00$ & $2.00 \pm 0.00$ & 0.16 \\
Repeat & $0.91 \pm 0.29$ & $1.05 \pm 0.50$ & 0.21 \\
Stage command & $2.78 \pm 0.74$ & $2.71 \pm 0.72$ & 0.42 \\
Read and execute & $0.43 \pm 0.51$ & $0.67 \pm 0.48$ & 0.01 \\
Speaking back a phrase & $0.39 \pm 0.50$ & $0.52 \pm 0.51$ & 0.09 \\
Copy diagram & $0.26 \pm 0.45$ & $0.48 \pm 0.51$ & 0.02 \\
\hline
\end{tabular}

$\mathrm{T} 0=$ evaluation of baseline (average \pm standard deviation); $\mathrm{T} 2=$ evaluation after 20 physiotherapy sessions (average \pm standard deviation); $* * *$ Student t-test paired for $\mathrm{T} 0$ and $\mathrm{T} 2$.

\section{DISCUSSION}

The sample consisted exclusively of elderly females, aged between 65 and 90 years, with predominance of those aged 80 or over and single, who were illiterate or poorly educated, and retired. This data points to a tendency towards aging among the elderly population, especially among women, suggesting an increase in the life expectancy of the population in various regions of Brazil, further evidenced by studies conducted in the cities of Fortaleza-Ceará, ${ }^{16}$ Recife-Pernambuco, ${ }^{17}$ João Pessoa-Paraíba, ${ }^{18}$ Brasília-Distrito Federal, ${ }^{19}$ Diamantina-Minas Gerais ${ }^{20}$ and Porto Alegre-Rio Grande do Sul. ${ }^{21}$

In this context, the predominance of elderly females can be attributed to their lower exposure to certain risk factors, especially at work, their lower prevalence of smoking and drinking, differences in their ability to cope with diseases and disabilities and, lastly, to the higher levels of coverage afforded by gynecological and obstetric care. ${ }^{22,23}$ The low or non-existent educational level of the elderly population is socio-demographically relevant as studies $^{24}$ report that these elderly individuals are between 4.5 to 5 times more likely to develop moderate/severe dependence, compromising their functionality and consequently their quality of life. The longer life expectancy of the group aged $\geq 80$ has been attributed mainly to the greater concern and care they tend to show in relation to diseases and preventive health care, to new patterns of behavior and to the attainment of a healthier lifestyle, as well as the national pattern of the increased feminization of old age. ${ }^{25,26}$

A considerable number of the elderly persons presented visual defects or reported ringing in their ears and obtained a positive result in the whisper test, while a few admitted having some hearing impairment. These results are similar to those found in the studies by Floriano \& Dalgalarrondo, ${ }^{27}$ Borges et al. ${ }^{28}$ and Menezes et al. ${ }^{29}$ These disorders 
lead to a reduction in communication capacity and to functional incapacity, which creates restrictions on mobility and subsequently leads to dependence, resulting in an even greater likelihood of falls and traumas in general. ${ }^{30}$ Most sensory changes associated with aging are inevitable; however, they may be tackled with a preventive, corrective and sometimes even curative approach, enabling at least the delay of these dysfunctions.

In the present study, the elderly population was classified almost entirely as oriented, and capable of obeying simple instructions; however, about half reported recurring forgetfulness and progressive worsening of its frequency. No studies were found which evaluated such cognitive characteristics specifically, with the assessment of cognitive function solely through utilization of cognitive tests to evaluate skills being common in literature. ${ }^{4,6}$ For Borges et al., ${ }^{31}$ elderly persons living in LTCFEs become increasingly sedentary and lose much of their autonomy which, allied to the aging process, can enhance cognitive decline. However, the study by Carneiro et al., ${ }^{16}$ performed with 59 elderly residents in two LTCFEs in the city of Fortaleza, Ceará, demonstrated that the elderly showed independence in carrying out their daily activities (food, personal hygiene, bathing, mobility and sphincter control), needing help just with movement on stairs and with small defects in memory.

The present study found that health promotion strategies carried out with institutionalized elderly persons provided improvements in their MMSE performance. These findings suggest that programs of guided intervention in health promotion activities, carried out through physiotherapy, are effective in optimizing the cognitive function of elderly residents of LTCFEs.

Irigaray et al. ${ }^{32}$ and Alves ${ }^{33}$ obtained results similar to the present study observing the effectiveness of group programs for cognitive rehabilitation. Apóstolo et al. ${ }^{34}$ also found that the development of a stimulation program for elderly people had positive effects on cognition. The authors applied the "Fazer a diferença" (PEC-FD) a Cognitive Stimulation Program (the Portuguese version of Making a Difference: An Evidence-based Group Program to Offer Cognitive Stimulation Therapy (CST) to People with Dementia), which addressed the following themes: physical games, sounds, childhood, food, current issues, portraits/ scenes, word association, creativity, object classification, orientation, use of money, playing with numbers, playing with words and team games, with two 45 minute sessions a week for seven weeks among a sample of 14 elderly persons, and showed that the group undergoing the PEC-FD program showed significant improvements in cognition, enhancing their autonomy and functional capacity.

Another study ${ }^{35}$ regarding the cognitive responsiveness of elderly participants in a cognitive training program, developed with 21 elderly persons over eight sessions using simulations of everyday tasks such as shopping - involving memorizing a grocery shopping list and simple mathematical calculations - as an approach strategy obtained results that pointed to a cognitive improvement mainly related to memory.

Some of the categories evaluated in this study showed no change or improvement, even after 20 interventions. Some observations are important in this respect: (1) there were elderly women whose initial performance was optimal in certain items and who were therefore unable to register improvement in their score in post-intervention data collection; (2) some elderly individuals had auditory and visual disorders that may have compromised their personal performance in the activities, with resultant repercussions on the overall evaluation of the LTCFE; (3) certain skills assessed by the MMSE, such as "attention and calculation", "read and execute" and "repeat a phrase" are partially dependent on and influenced by level of education, and as such these items revealed small changes or no alteration due to the fact that the study population was predominantly illiterate or poorly educated; (4) and finally, as the activities carried out with the elderly were not organized so that all the skills covered by the MMSE were taught in equal measure in each round of 10 sessions, it is possible that some categories were worked on more 
than others, explaining the superior performance associated with certain capabilities.

It is estimated that for each year lived above life-expectancy, six to nine months, or close to $80 \%$, are spent in a state of incapacity. ${ }^{36}$ Health promotion has developed as a response to this challenge of achieving old age without disability, encompassing actions directed at strengthening the physical and mental abilities of individuals, as well as actions directed at changes in social, environmental and economic conditions, in order to lessen their impact on public and individual health. ${ }^{37}$ Hence the importance of the participation of older people in health promotion programs that focus on prevention of disabilities as a priority.

Finally, limiting factors for the study as a whole were the small sample size and the intervention plan, which was not organized to focus on all the assessed skills with the same intensity. Furthermore, it is important to highlight the scarcity of literature, especially Brazilian, focused on the impacts of health promotion intervention programs on cognitive performance in the elderly. However, despite this, this study may be considered valid, since the proposed objectives were achieved, further demonstrating to the academic community the importance of programs and of university extension projects to explain their positive effects on the health of the population.

For future studies, the use of the following is suggested: a type of instrument other than the MMSE for cognitive assessment; a larger sample of both genders with a more homogeneous clinical profile; a case-control program with greater methodological rigor, where the activities to be carried out are well defined and divided beforehand so that equal time is devoted to all the skills to be analyzed, always aimed at achieving results which remain relevant for the long term and can be generalized for the everyday cognitive challenges of the aging population.

It should be noted that an aging population also represents a greater burden of disease in the population, as well as higher levels of incapacity and increased use of health services. Prevention is the key to improving the current situation and has shown to be effective at every level, including in the later stages of life. Identifying the health status of the elderly enables targeted interventions in order to meet their demands and improve their quality of life. Proper planning, directed at the real needs of this population, contributes to the wellbeing, independence and dignity of such elderly individuals, in order to provide a more healthy aging process, in which quality of life is added to years, and not just years to life.

\section{CONCLUSION}

Performance in the Mini Mental State Examination improved after the performance of health promotion activities, optimizing the cognitive function of the institutionalized elderly persons, thus contributing to a better quality of life.

A number of issues related to interventional cognitive training for healthy elderly persons and/ or patients with deficits of this nature remain little studied in Brazil. The relevance of these issues should be noted, as they are themes directly related to the health, independence, autonomy and quality of life of the elderly.

\section{REFERENCES}

1. World Health Organization. Knowledge translation on ageing and health: a framework for policy development. Geneve: WHO; 2012.

2. Freitas MS, Queiroz TA, Sousa JAV. O significado da velhice e da experiência de envelhecer para os idosos. Rev Esc Enferm USP 2010;44(2):407-12.
3. Correia M. Perfil cognitivo em idosas de dois serviços públicos em São Luís-MA. Rev Psiquiatr Clín 2008;35(4):131-7.

4. Borges LJ, Benedetti TRB, Mazo GZ. Rastreamento cognitivo e sintomas depressivos em idosos iniciantes em programa de exercício físico. J Bras Psiquiatr 2007;56(4):273-9. 
5. Ávila R, Bottino CMC. Atualização sobre alterações cognitivas em idosos com síndrome depressiva. Rev Bras Psiquiatr 2006;28(4):316-20.

6. Dias RG, Streit IA, Sandreschi PF, Benedetti TRB, Mazo GZ. Diferenças nos aspectos cognitivos entre idosos praticantes e não praticantes de exercício físico. J Bras Psiquiatr 2014;63(4):326 -31.

7. Azevedo LM, Oliveira KMV, Nunes VMA, Alchieri JC. Perdas da capacidade funcional em idosos institucionalizados no município de Natal/RN. J Res Fundam Care 2014;6(2):485-92.

8. Santos SSC, Cavalheiro BC, Silva BT, Barlem ELD, Feliciani AM, Valcarenghi RV. Avaliação multidimensional do idoso por enfermeiros brasileiros: uma revisão integrativa. Ciênc Cuid Saúde 2010;9(1):129-36.

9. Gonçalves LHT, Silva AH, Mazo GZ, Benedetti TRB, Santos SMA, Marques S. O idoso institucionalizado: avaliação da capacidade funcional e aptidão física. Cad Saúde Pública 2010;26(9):1738-46.

10. Carvalho MP, Luckow ELT, Peres W, Garcias GL, Siqueira FCV. O envelhecimento e seus fatores de risco associados. Rev Bras Ciênc Envelhec Hum 2011;8(2):265-71.

11. Folstein MF, Folstein SE, McHugh PR. "Mini-mental state": a practical method for grading the cognitive state of patients for the clinician. J Psychiatr Res 1975;12(3):189-98.

12. Bertolucci PHF, Brucki SMD, Campacci SR, Juliano Y. O miniexame do estado mental em uma população geral: impacto da escolaridade. Arq Neuropsiquiatr 1994;52(1):1-7.

13. Brucki SMD, Nitrini R, Caramelli P, Bertolucci PHF, Okamoto IH. Sugestões para o uso do mini-exame do estado mental no Brasil. Arq Neuropsiquiatr 2003; 61(3B):777-81.

14. Brasil. Ministério da Saúde, Secretaria de Atenção à Saúde, Departamento de Atenção Básica. Envelhecimento e saúde da pessoa idosa. Brasília: Ministério da Saúde; 2006. 192 p. (Cadernos de Atenção Básica, n. 19); (Série A. Normas e Manuais Técnicos).

15. Brasil. Conselho Nacional de Saúde. Resolução 466/12, de 12 de Dezembro de 2012. Diretrizes e Normas de Pesquisa em Seres Humanos. Brasília, DF: Sistema de Legislação da saúde; 2000.

16. Carneiro FR, Brasileiro IC, Vasconcelos TB, Arruda VP, Florêncio RS, Moreira TMM. Independência funcional de idosas residentes em instituições de longa permanência. Acta Fisiatrica 2012;19(3):156-60.

17. Dantas CMHL, Bello FA, Barreto KL, Lima LS. Capacidade funcional de idosos com doenças crônicas residentes em instituições de longa permanência. Rev Bras Enferm 2013;66(6):914-20.
18. Lima CLJ, Costa MML, Ferreira JDL, Silva MA, Ribeiro JKS, Soares MJGA. Perfil sociodemográfico e clínico de idosos institucionalizados. Rev Enferm UFPE 2013;7(10):6027-34.

19. Oliveira MPF, Novaes MRCG. Perfil socioeconômico, epidemiológico e farmacoterapêutico de idosos institucionalizados de Brasília, Brasil. Ciênc Saúde Coletiva 2013;18(4):1069-78.

20. Silva ME, Cristianismo RS, Dutra LR, Dutra IR. Perfil epidemiológico, sociodemográfico e clínico de idosos institucionalizados. Rev Enferm Cent-Oeste Min 2013;3(1):569-76.

21. Souza CC, Valmorbida LA, Oliveira JP, Borsatto AC, Lorenzini M, Knorst MR, et al. Mobilidade funcional em idosos institucionalizado e não institucionalizados. Rev Bras Geriatr Gerontol 2013;16(2):285-93.

22. Garcia RA, Carvalho JAM. O envelhecimento da população brasileira: um enfoque demográfico. Cad Saúde Pública 2003;19(3):725-33.

23. Giatti L, Barreto SM, Lima MFC. Condições de saúde, capacidade funcional, uso de serviços de saúde e gastos com medicamentos da população idosa brasileira: um estudo descritivo baseado na pesquisa Nacional por Amostra de domicílios. Cad Saúde Pública 2003;19(3):735-43.

24. Parayba MI, Veras R. Diferenciais sociodemográficos no declínio funcional em mobilidade física entre os idosos no Brasil. Ciênc Saúde Coletiva 2008;13(4):1257-64.

25. Celich KLS. Domínios de qualidade de vida e capacidade para a tomada de decisão em idosos participantes de grupos da terceira idade [tese na Internet]. Porto Alegre: PUCRS; 2008 [acesso em 17 jun 2014]. Disponível em: http://repositorio.pucrs.br/ dspace/bitstream/10923/3587/1/000405317Texto \%2 BCompleto-0.pdf.

26. Herévia VBM, Corteletti IA, Casara MB, Sassi A, Ramalho MHS, Borges MNF. A realidade do idoso institucionalizado. Textos envelhecimento 2004;7(2):1-15.

27. Floriano PJ, Dalgalarrondo P. Saúde mental, qualidade de vida e religião em idosos de um Programa de Saúde da Família. Rev Bras Psiquiatr 2007; 56(3):162-70.

28. Borges LL, Garcia PA, Ribeiro SOV. Características clínico-demográficas, quedas e equilíbrio funcional de idosos institucionalizados e comunitários. Fisioter Mov 2009;22(1):53-60.

29. Menezes RL, Bachion MM, Souza JT, Nakatani AYK. Estudo longitudinal dos aspectos multidimensionais da saúde de idosos institucionalizados. Rev Bras Geriatr Gerontol 2011;14(3):485-96. 
30. West S, Sommer A. Prevention of blindness and priorities for the future. Bull World Health Organ 2001;79(3):244-48.

31. Borges MGS, Rocha LR, Couto EAB, Mancini PC. Comparação do equilíbrio, depressão e cognição entre idosas institucionalizadas e não-institucionalizadas. Rev CEFAC 2013;15(5):1073-9.

32. Irigaray TQ, Gomes Filho I, Schineider RH. Efeitos de um treino de atenção, memória e funções executivas na cognição de idosos saudáveis. Psicol Reflexão Crít 2012;25(1):188-202.

33. Alves VHS. Estudo piloto de um programa de reabilitação cognitivo grupal e o seu impacto no funcionamento cognitivo e não-cognitivo de idosos sob resposta social [dissertação na Internet]. Coimbra: Instituto Superior Miguel Torga; 2012 [acesso em 20 jun. 2014] Disponível em: https://www.academia. edu/3850265/Estudo_piloto_de_um_programa_de_ reabilitacao_cognitivo_grupal_e_o_seu_impacto_ no_funcionamento_cognitivo_e_nao-cognitivo_
Preliminary_study_of_a_group_cognitive_ rehabilitation_program_and_its_impact_on_ cognitive_and_non-cognitive_functioning_

34. Apóstolo JLA, Cardoso AFB, Marta LMG, Amaral TIO. Efeito da estimulação cognitiva em idosos. Rev Enferm Ref 2011;3(5):45-58.

35. Silva BLT, De Oliveira ACV, Paulo DLV, Malagutti MP, Danzini VMP, Yassuda MS. Cognitive training for elderly adults based on categorization strategies and calculations similar to everyday tasks. Rev Bras Geriatr Gerontol 2011;14(1):65-74.

36. Cassel CK. Successful aging: how increase life expectancy and medical advances are changing geriatric care. Geriatrics 2001;56(1):35-9.

37. Montenegro SMRS, Silva CAB. Os efeitos de um programa de fisioterapia como promotor de saúde na capacidade funcional de mulheres idosas institucionalizadas. Rev Bras Geriatr Gerontol 2007;10(2):161-78. 